\title{
PID Control Performance Improvement for a Liquid Level System using Parameter Design
}

\author{
Barış Şimşek $^{* 1}$, Gözde Ultav², Vedat Arda Küçük ${ }^{3}$, Yusuf Tansel İç ${ }^{4}$ \\ Accepted $3^{\text {rd }}$ September 2016
}

\begin{abstract}
In this study, it is aimed to reduce the variability of parameters in the liquid level system controlled by PID controller for a laboratory scale device. An integrated methodology consisting of experimental design and feedback PID (proportional-integralderivative) controller was proposed to optimize and control the deviation from the average value in the offset value, variability in the offset value and the time to reach the set value in this liquid level system. The optimal valve opening levels that minimizes the average of the offset value $(\mu)$, variance $\left(\mathrm{s}^{2}\right)$ and the first time to reach the set value $(\mathrm{t})$ were determined as $40 \%, 5 \%, 50 \%$ and $80 \%$, respectively, using TOPSIS (Technique for Order Preference by Similarity to an Ideal Solution)-based Taguchi method by Minitab®. A quite successful control was established in the verification test which performed with specified levels of optimal valve opening. Recovery rates in the control performance before and after optimizing the parameter were calculated as $9.53 \%$ in the deviation from the average value in the offset values, $29.37 \%$ in the variability in the offset value and $11.27 \%$ in the time to reach the set value. MATLAB/Simulink was used to simulate the liquid level system.
\end{abstract}

Keywords:Laboratory Scale Liquid Level System, TOPSIS based Taguchi Parameter Design, PID Controller and Performance Improvement

\section{Introduction}

Liquid level loops are frequently encountered in many process industries such as waste water management systems and petrochemical processes [1] - [4]. Especially in the petroleum industry, liquid level is a crucial parameter for production at oil wells [5]. In recent years, many researchers studied on controlling of liquid level systems [6]. Sbarbaro and Ortega (2007) proposed a new approach to control the multi-tanks systems [7]; Almutairi et al. (2007) proposed several sliding mode control diagrams for the coupled tanks [8]. Lee and Shin (2009) applied constrained control to liquid level system using conventional PI (proportional-integral) controller [1]. Zhang et al. (2011) modelled and controlled the liquid level in a coke fractionation tower using non-linear based predictive control [9]. Noel and Pandian (2014) proposed an integrated methodology including artificial neural network based reinforcement learning approach for controlling of a nonlinear liquid level system [10]. Sadeghi et al. (2014) designed a method based on parallel distributed compensation via fuzzy Takagi-Sugeno model for a liquid level system [11]. Singh et al. (2014) reduced flow rate fluctuation for tank in series with PI controller [12]. Zhang et al. (2014) offered PI controller based on predictive functional control for liquid level in a coke fractionation tower [9], [13]. In the literature, many studies contain process optimization and control applications have proposed for various industrial areas. Some of these studies are as follows; Tao et al. (2014) applied predictive control based PID design with genetic algorithm for chamber

\footnotetext{
${ }^{1}$ Chemical Engineering Department, Faculty of Engineering, ÇankırıKaratekinUniversity, Uluyazi Campus, 18100, Çankırı/Türkiye * Corresponding Author:barissimsek@karatekin.edu.tr Note: This paper has been presented at the $3^{\text {rd }}$ International Conference on Advanced Technology \& Sciences (ICAT'16) held in Konya (Turkey), September 01-03, 2016.
}

pressure in coke furnace [13], Zhang et al performed model predictive control optimization based PID control for temperature in an industrial surfactant reactor [14], Zhang and Yang (2014) developed an incremental-PID-controlled particle swarm optimization algorithm for EGG-data-based estimation of operator functional state [15]. Sahu et al. (2015) proposed teaching-learning based optimization algorithm based fuzzy-PID controller for automatic generation control of multi-area power system [16], Gizi et al. (2015) formulated an integrated approach programmable logic controller-fuzzy PID methodology to determine optimal PID parameter in automatic voltage regulator [17].

Many difficulties are experienced in liquid level control systems owing to the variability in the parameters and flow resistance [3]. Parameter variations that should be controlled can be originated from pumps, agitators or the natural causes [3]. In this study, it is aimed to reduce the variability of parameters in the laboratory scale liquid level system controlled by PID controller. Purpose of reduction of parameters' variability and noise effect with the methodology including multi-criteria decision making (MCDM) based Design of Experiment (DoE) for finding optimal valve opening levels and process control performance improvement. Moreover, the improvement rate was also specified by finding valves' opening levels to optimize the process control performance. Giving a positive and negative effect on the system, system performance was evaluated after the parameter optimization. Matlab/Simulink ${ }^{\circledR}$ was used to simulate the laboratory scale liquid level system (LSLLS).

\section{Proposed Materials \& Methodology}

\subsection{Materials}

Liquid level control techniques can be applied experimentally by a LSLLS built up from standard industrial parts (Figure 1). It is 
possible to observe the control techniques used in the industry. P, PI and PID control methods can be examined experimentally with LSLLS. The reaction of the control data can be measured with changing operation conditions. Pressure tracking can be done in four different points via an analogue type industrial manometer. Liquid level in the plexi tank can be measured by HK Instruments DPT-R8 differential pressure sensor. Accuracy of DPT is $\pm \% 1.5$ or $\pm 6 \mathrm{~Pa}$ under $250 \mathrm{~Pa}$. Control data can be recorded by the Pangu KT104 digital data recorder. It can record and show process data graphically and visually. Width of the cylindrical liquid tank of LSLLS is $75 \mathrm{~cm}$ and height of the tank is $200 \mathrm{~cm}$. Experimental set has a pneumatic proportional valve consist of Young Tech Instruments YT100 electrical junction box, positioner, PVD TPA40 pneumatic actuator and an 1.0 inch inner diameter ball valve.

Valve no. 1 breaks the water come from the water pump, Valve no. 2 is the by-pass valve connected to pneumatic proportional valve, Valve no. 3 is located at the plexi tank water inlet and Valve no. 4, drain valve, is located at the plexi tank water outlet. The block diagram of the LSLLS was given in Figure 2.

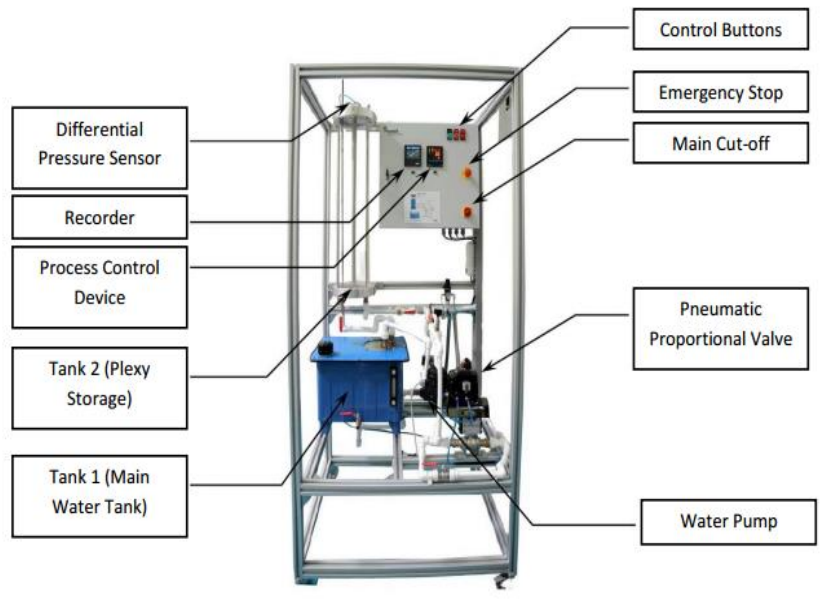

Figure1.Laboratory scale liquid level system

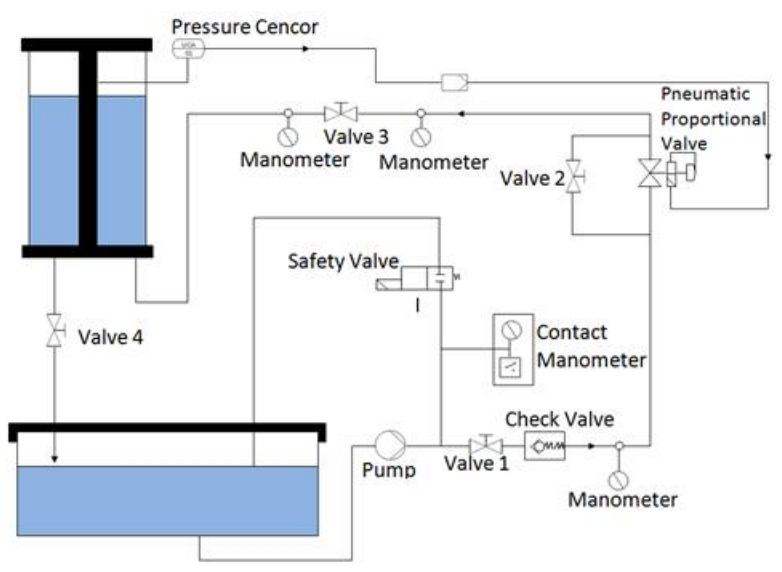

Figure2.Block diagram of laboratory scale liquid level system

\subsection{Proposed Methodology}

Proposed methodology contains two stages including parameter optimization and control. In first stage, optimal valve opening levels were determined to minimize the deviation from the average value in the offset value, variability in the offset value and the time to reach the set value in this liquid level system using TOPSIS based Taguchi methodology. In second stage, process control performance of the system was monitored via optimum valve opening; dynamic behavior of LSLLS with positive and negative step change was examined, closed-loop block diagram was established by Matlab/Simulink ${ }^{\circledR}$ and process control performance improvement rate was calculated between former and optimal valve opening levels. Flow diagram (including 10 flow steps used in the study in process control performance optimization of LSLLS) is given in Figure 3.

\subsection{Determining Performance Criteria for The Success of Process Control}

Three performance criteria for the successfull process control were defined as deviation from the average value in the offset value, variability in the offset value and the time to reach the set value. Target values and weights of performance criteria were given in Table 1.

\begin{tabular}{|c|c|}
\hline PARAMETER OPTIMIZATION & PROCESS CONTROL \\
\hline STEP1 1 & STEPC \\
\hline $\begin{array}{l}\text { - Determine LLS optimization and control } \\
\text { objectives }\end{array}$ & $\begin{array}{l}\text { - Calculation the PID parameters with } \\
\text { statistical model definition }\end{array}$ \\
\hline -DTE2 2 etermine performance criteria for the & STIEP7 \\
\hline success of process control & $\begin{array}{l}\text { - Development of a closed loop feedback } \\
\text { block diagram using MATLAB }\end{array}$ \\
\hline - Determination of parameters and their & Simulink \\
\hline $\begin{array}{l}\text { ITVEP } 4 \\
\text { STVP }\end{array}$ & STEP 8 \\
\hline $\begin{array}{l}\text { - Determine optimization and control } \\
\text { methodology }\end{array}$ & - Obtaining the transfer function of LLS \\
\hline $\begin{array}{l}\text {-Implement of Taguchi design with } \\
\text { TOPSIS } \\
\text { - Obtain experiment results using PID } \\
\text { controller }\end{array}$ & $\begin{array}{l}\text { Examination of the dynamic behaviour of } \\
\text { LLS giving positive and negative step } \\
\text { change }\end{array}$ \\
\hline $\begin{array}{l}\text { - Calculation of offset mean, offset } \\
\text { variation and time to reach the setpoint } \\
\text { - Optimization using TOPSIS based } \\
\text { Taguchi design using MINITAB } \mathbb{} \\
\text { - Validation experiment }\end{array}$ & $\begin{array}{l}\text { - Calculation of process control } \\
\text { performance improvement between } \\
\text { former and oprimal conditions }\end{array}$ \\
\hline
\end{tabular}

Figure3.Proposed process optimization and control methodology

Offset value is steady-state difference between the set point which is $60 \mathrm{~cm}$ with the actual point obtained in liquid level control system. The average of these values was defined as mean of the offset values, the variance of these values was defined as variance of the offset values, respectively. Time to reach the set point was described as the first time to reach $60 \mathrm{~cm}$. 8th, 7th and 4 th values were designated to mean of the offset values, the variance of these values and time to reach the set point, respectively. All criteria representing process control performance are required to be minimized.

\subsection{Determining Levels of Performance Criteria}

Each globe valve which has $1 / 2$ inch inner diameter, effect on performance criteria has three levels and their description was shown in Table 2. Tank no. 1 filled with city water was used as fluid in the system. Process parameters, valve opening levels, were set before each experiment's implementation. The system was run for twenty minutes. In all experiments, an industrial type PIDcontroller (Ordel AC991) was utilized to control the liquid level at Tank no. 2. An industrial differential pressure transmitter which can measure pressure difference up to 7 kPawas used to effectively measure the fluid level. Measurements were sent to PID controller as electrical signals. PID controller calculates valve opening position of pneumatic proportional valve, required to control system. Experimental data were collected by industrial data-logger during the system run.

\subsection{TOPSIS Based Taguchi Design and PID Controller Algorithm}

TOPSIS based Taguchi Method is a design of experiment technique takes only linear effectsinto account was used to determine optimal valve opening levels. The details of this 
Table 1. Performance Criteria and Their Weights

\begin{tabular}{|c|c|c|c|c|c|}
\hline Performance Criteria & Symbol & Description & Target values & Weights & $\begin{array}{c}\text { Normalized } \\
\text { Weight }\end{array}$ \\
\hline 1 & $\mu$ & mean of the offset values $(\mathrm{cm})$ & Smaller is better & 8 & 0.421 \\
\hline 2 & $s^{2}$ & variance of the offset values $\left(\mathrm{cm}^{2}\right)$ & Smaller is better & 7 & 0.368 \\
\hline 3 & $t$ & time to reach the set point $(\mathrm{s})$ & Smaller is better & 4 & 0.211 \\
\hline & & & Total & 19 & 1.0 \\
\hline
\end{tabular}

methodology were expressed in Şimşek et al. [18]. PID controller algorithm which is dominant type in feedback controller finds wide application coverage in industry [19]. Macro-scaled continuous process contains between five hundred with five thousand feedback controller for various process variables [19]. $97 \%$ of the controllers used are some forms of PID controller. Transfer function of PID control algorithm parallel form is given in equation (1) [19];

$$
\frac{P^{\prime}(s)}{E(s)}=K_{C}\left(1+\frac{1}{\tau_{I} s}+\tau_{D} s\right)
$$

Proportional gain, integral gain, derivative gain are tuning parameters which are symbolized as $\mathrm{K}_{\mathrm{c}}, \tau_{\mathrm{I}}$ and $\tau_{\mathrm{D}}$, respectively [19]. In this study, Matlab PID tuner was used to determine the process control parameters.

\subsection{Development of a Theoretical Model for Simulink}

Several model approaches can be used for process control applications. Theoretical models which are obtained by process physics and chemistry can be used in industry. Development of theoretical models may not be a practical way when model requires process variables and unknown parameters (i.e. physical and chemical properties) including many equations. Development of an empirical model from experimental data directly can be an alternative approach [19].

\section{Results and Discussion}

\subsection{Results}

In this study, a Taguchi's $\left(3^{4}\right)$ orthogonal array was used to implement the experiments and results are given in Table 3 [20]. In Table 3, columns 2-5 represent the four control factors and their levels. Findings relevant to the deviation from the average value in the offset value, variability in the offset value and the time to reach the set value in this liquid level system were given in columns 6-8. Table 3 also contains PID tuning parameters such as proportional gain, integral gain, derivative gain which is shown in columns 9-11.

\subsection{TOPSIS Based Taguchi Design}

In this study a Taguchi orthogonal array $\left(\mathrm{L}_{9}: 3^{4}\right)$ was selected to implement the experiments. Signal to noise ratios $(\mathrm{S} / \mathrm{N})$ were calculated for the smaller the better type responses and given in columns 2-4. Let $n_{i j}$ be the $\mathrm{S} / \mathrm{N}$ for the response $\mathrm{j}$ of experiment $\mathrm{i}$ and let $y_{i j k}$ be the experiment result for the response $j$ of experiment $i$, in the $k^{\text {th }}$ replication; $\mathrm{n}$ is the total number of replications [18], [21]. The calculation of the $\mathrm{S} / \mathrm{N}$ ratio can then be determined as [22]; $n_{i j}=-\log K_{C}\left(\frac{1}{n} \sum_{k=1}^{n} y_{i j k}{ }^{2}\right)$

In Table 4, columns 5-7 are shown as decision matrix which is essential step of the TOPSIS method [26]. The positive ideal solution $\left(\mathrm{S}_{\mathrm{i}}^{+}\right)$, and negative ideal solutions $\left(\mathrm{S}_{\mathrm{i}}^{-}\right)$and $\mathrm{C}_{\mathrm{i}}{ }^{*}(\mathrm{i}=1 \ldots .9)$, are the surrogate responses for the multi-response minimization problem [18].

The average responses by factor levels can be designated by utilizing the additive property [18], [23]. Their associated factor effect plots are given in Figure 4 [18]. Since the effect values are smaller- the-better, normalization methods caused the final parameter design of $A_{2} B_{2} C_{3} D_{2}$ which is given in Table 5 .

\subsection{Validation of experiment and PID tuning parameters' calculation}

In order to confirm the optimum valve opening levels achieved using the TOPSIS based Taguchi method, an experimental study was implemented to check whether the deviation from the average value in the offset value, variability in the offset value and the time to reach the set value could really be minimized by the proposed optimum valve opening levels. The confirmation study improvement for mean of the offset values, variance of the offset values and time to reach the results which are given in Table 6 demonstrated that proposed results satisfies the expected set point. PID tuning parameters of validation experiments were calculated as 0.57 for proportional gain, 4.54 for integral gain, and 13.64 for derivative gain using well-known statistical model definition techniques.

\subsection{Development of a Closed-Loop Feedback Block Diagram Using Matlab/Simulink ${ }^{\circledR}$}

Transfer function of a laboratory scale liquid level system can be modeled utilizing orifice and mass balance equation to describe the dynamics of chemical process given in Seborget. al. [19]. A block diagram representing the laboratory scale liquid level system was obtained by Matlab/Simulink ${ }^{\circledR}$ tool can be seen in Figure 5. PID controller tuning parameters were received as 0.57 for proportional gain, 4.54 for integral gain, 13.64 for derivative gain. System response against step change can be seen in Figure 6.

\section{Conclusion}

This research offered an integrated process optimization which is MCDM based experimental design and process control methodology to improve process control performance in a laboratory scale liquid level system. Following the TOPSIS based Taguchi procedure, process control performance of the system was monitored using optimal valve opening levels. 
Table 2.Valve Opening Levels

\begin{tabular}{|c|c|c|c|c|}
\hline \multirow{3}{*}{ Parameters } & \multirow{3}{*}{ Description } & \multicolumn{3}{|c|}{ Levels } \\
\hline & & 1 (uncoded values) & 2 (uncoded values) & 3 (uncoded values) \\
\hline & & First level & Second level & Third level \\
\hline $\mathrm{X}_{1}$ & First Valve opening (\%) & 30 & 40 & $\underline{50}$ \\
\hline $\mathrm{X}_{2}$ & Second Valve opening $(\%)$ & $\underline{0^{*}}$ & 5 & 10 \\
\hline $\mathrm{X}_{3}$ & Third Valve opening (\%) & 30 & 40 & $\underline{50}$ \\
\hline $\mathrm{X}_{4}$ & Fourth Valve opening $(\%)$ & 70 & $\underline{80}$ & 90 \\
\hline
\end{tabular}

Underlined values are the predicted levels before the parameter optimization*

Table 3.Findings Were Obtained In All Experiments Using PID Controller

\begin{tabular}{|c|c|c|c|c|c|c|c|c|c|}
\hline \multirow{2}{*}{$\begin{array}{l}\text { Exp. } \\
\text { No }\end{array}$} & \multirow[t]{2}{*}{$\mu$} & \multirow{2}{*}{$\frac{s^{2}}{\mathrm{~S} / \mathrm{N} \text { ratios }}$} & \multirow[t]{2}{*}{$\mathrm{t}$} & \multicolumn{3}{|c|}{ Weighted Normalized Decision Matrix } & \multirow[b]{2}{*}{$\mathrm{S}_{\mathrm{i}}^{+}$} & \multirow[b]{2}{*}{$\mathrm{S}_{\mathrm{i}}^{-}$} & \multirow[b]{2}{*}{$\mathrm{C}_{\mathrm{i}}{ }^{*}$} \\
\hline & & & & $\mathrm{V}_{\mathrm{ij} 1}$ & $\mathrm{~V}_{\mathrm{ij} 2}$ & $\mathrm{~V}_{\mathrm{ij} 3}$ & & & \\
\hline 1 & -15.8343 & -31.9222 & -39.4626 & -0.217 & -0.132 & -0.071 & 0.131 & 0.005 & 0.037 \\
\hline 2 & -9.6807 & -28.9923 & -35.7066 & -0.133 & -0.120 & -0.064 & 0.046 & 0.086 & 0.654 \\
\hline 3 & -9.6999 & -30.4288 & -42.1442 & -0.133 & -0.126 & -0.076 & 0.049 & 0.085 & 0.635 \\
\hline 4 & -9.6516 & -29.6654 & -40.0864 & -0.132 & -0.122 & -0.072 & 0.046 & 0.086 & 0.649 \\
\hline 5 & -6.3966 & -27.3113 & -37.3846 & -0.088 & -0.113 & -0.067 & 0.003 & 0.131 & 0.978 \\
\hline 6 & -8.6912 & -28.7228 & -38.6900 & -0.119 & -0.119 & -0.070 & 0.032 & 0.099 & 0.754 \\
\hline 7 & -7.9548 & -28.8834 & -40.5877 & -0.109 & -0.119 & -0.073 & 0.024 & 0.109 & 0.820 \\
\hline 8 & -9.5153 & -29.3007 & -39.4626 & -0.131 & -0.121 & -0.071 & 0.044 & 0.088 & 0.665 \\
\hline 9 & -11.8116 & -32.3152 & -36.5215 & -0.162 & -0.133 & -0.066 & 0.077 & 0.056 & 0.421 \\
\hline
\end{tabular}

Table 4. Optimum Parameter's Levels

\begin{tabular}{|l|l|l|l|}
\hline Factors & $X_{1}$ & $X_{2}$ & $X_{3}$ \\
\hline Level 1 & 0.4424 & 0.5019 & 0.4855 \\
Level 2 & $\mathbf{0 . 7 9 3 3}$ & $\mathbf{0 . 7 6 5 8}$ & 0.4787 \\
Level 3 & 0.6354 & $\mathbf{0 . 7 4 2 5}$ & $\mathbf{0 . 8 1 0 8}$ \\
\hline Optimal factor levels & & 2 & 0.6034 \\
\hline
\end{tabular}

*optimum levels were shown in bold font

Table 5.Anticipated Improvement In Optimum Condition

\begin{tabular}{|c|c|c|c|c|c|}
\hline Responses & Description & $\begin{array}{c}\text { Estimated mixture } \\
\text { levels before Taguchi } \\
\text { experiments } \\
A_{3} B_{1} C_{3} D_{2} \\
\end{array}$ & $\begin{array}{c}\text { Optimal mixture } \\
\text { levels after Taguchi } \\
\text { experiments } \\
A_{2} B_{2} C_{3} D_{2} \\
\end{array}$ & $\begin{array}{l}\text { Improvement rate } \\
(\mathrm{dB})\end{array}$ & $\begin{array}{c}\text { The percentage } \\
\text { of improvement } \\
(\%)\end{array}$ \\
\hline 1 & $\begin{array}{l}\text { mean of the offset values } \\
\qquad(\mathrm{cm})\end{array}$ & 2.49884 & 2.260758 & 0.238082 & 9.53 \\
\hline 2 & $\begin{array}{c}\text { variance of the offset } \\
\text { values } \\
\left(\mathrm{cm}^{2}\right)\end{array}$ & 27.8080 & 19.63998 & 8.16802 & 29.37 \\
\hline 3 & $\begin{array}{l}\text { time to reach } \\
\text { the set point } \\
(\mathrm{s})\end{array}$ & 107 & 95 & 12 & 11.27 \\
\hline
\end{tabular}




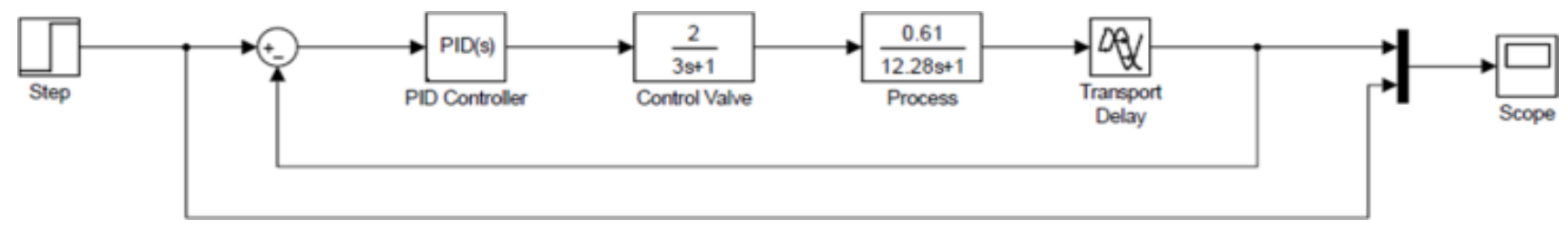

Figure 5.Simulation model of laboratory scale liquid level system

The validation experiment illustrated that the difference in process control performance between the optimal valve opening levels and estimated valve opening levels are significant.

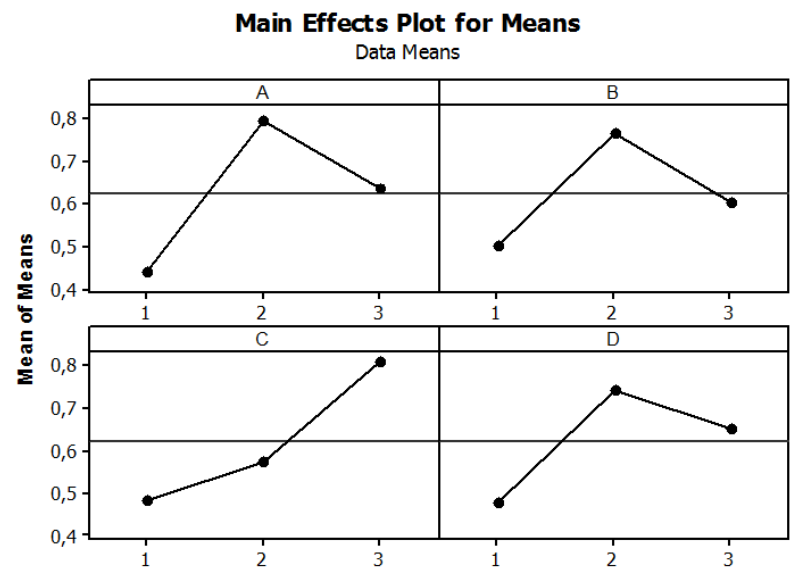

Figure4.Means plots for factor effects using vector normalization

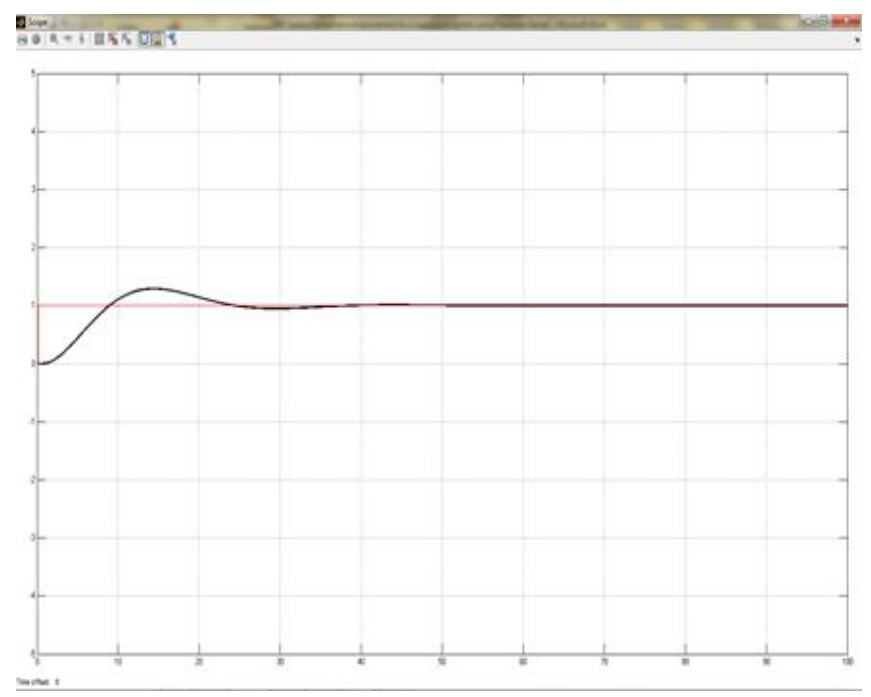

Figure6.System response against step change

Improvement of parameters between valve opening levels and estimated valve opening levels were calculated as follows; mean of the offset values average, $9.53 \%$, variance of the offset values, $29.37 \%$ and time to reach theset point, $11.27 \%$. In addition, improvement of parameters between valve opening levels with a positive step change and estimated valve opening levels were calculated as follows; mean of the offset values average, $34.79 \%$, variance of the offset values, $53.57 \%$ and time to reach the set point, $68.08 \%$. Furthermore, improvement of parameters between valve opening levels with a positive step change and estimated valve opening levels were calculated as follows; mean of the offset values average, $58.97 \%$, variance of the offset values, $11.22 \%$ and time to reach the set point, $21.50 \%$. It can be seen from the results of system behavior, that they satisfied the expected success process control performance of LSLLS (Figure 7).

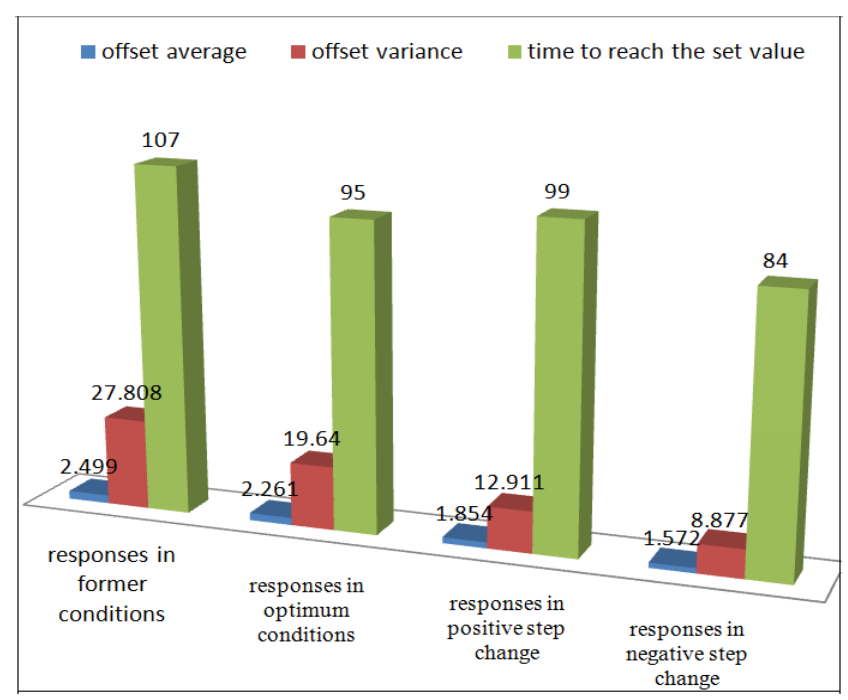

Figure7.System's responses in different conditions

\section{References}

[1] M. Lee, J. Shin, "Constrained optimal control of liquid level loop using a conventional proportional-integral controller", Taylor and Francis, Chem. Eng. Commun. vol. 196, pp. 729-745, 2009.

[2] Q. Wang, L. Xing, X. Shi, "Decoupling control of three tank liquid level systems based on feed forward compensation", Proceedings of Chinese Control and Decision Conference (CCDC), pp. 5863- 5866, 2009.

[3] R. Paul, A. Sengupta, R.R. Pathak, "Wavelet based denoising technique for liquid level system", Measurement, vol. 46, pp. 1979-1994, 2013.

[4] R. Zhang, A. Xue, S. Wang, "Modeling and nonlinear predictive functional control of liquid level in a coke fractionation tower", Chemical Engineering Science, vol. 66 pp. 6002-6013, 2011.

[5] G. Peng, J. He, S. Yang, W. Zhou, "Application of the fiber-optic distributed temperature sensing for monitoring the liquid level of producing oil wells", Measurement, vol. 58, pp. 130-137, 2014.

[6] Z. Aydoğmuş, "Implementation of a fuzzy-based level control using SCADA", Expert Systems with Applications, vol. 36, pp. 6593-6597, 2009.

[7] D. Sbarbaro, R. Ortega, "Averaging level control of multiple tanks: A passivity based approach", Journal of Process Control. Elsevier, 2007.

[8] N.B. Almutairi, M. Zribi, J. Hu, K. Bai, "Sliding mode control of coupled tanks", Mechatronics, Elsevier, 2007.

[9] R. Zhang, S. Wu, F. Gao, "Improved PI controller based on predictive functional control for liquid level regulation in a coke fractionation tower", J. Process Control, vol. 24, pp. 125-132, 2014. 
[10] M.M. Noel, B.J. Pandian, "Control of a nonlinear liquid level system using a new artificial neuralnetwork based reinforcement learning approach" Applied Soft Computing, vol. 23, pp. 444-451, 2014.

[11] M.S. Sadeghi, B. Safarinejadian, A. Farughian, "Parallel distributed compensator design of tank level control based on fuzzy Takagi-Sugeno model”, Applied Soft Computing, vol. 21, pp. 280-285, 2014.

[12] A.P. Singh, S. Mukherjee, M. Nikolaou, "Debottlenecking level control for tanks in series", Journal of Process Control, vol. 24, pp. 158-171, 2014.

[13] J. Tao, Z. Yu, Y. Zhu, "PFC Based PID Design using Genetic Algorithm for Chamber Pressure in a Coke Furnace", Chemometrics and Intelligent Laboratory Systems, vol. 137 pp. 155-161, 2014.

[14] R. Zhang, S. Wu, R. Lu, F. Gao, "Predictive Control Optimization based PID Control for Temperature in an Industrial Surfactant Reactor", Chemometrics and Intelligent Laboratory Systems, vol. 135, pp. 48-62, 2014.

[15] J. Zhang, S. Yang, "An incremental-PID-controlled Particle Swarm Optimization Algorithm for EEG-data-based Estimation of Operator Functional State", Biomedical Signal Processing and Control, vol. 14, pp. 272-284, 2014.

[16] B.K. Sahu, S. Pati, P.K. Mohantya, S. Panda, "TeachingLearning based Optimization Algorithm based fuzzy-PID Controller for Automatic Generation Control of Multi-Area Power System", Applied Soft Computing, vol. 27 pp. 240249, 2015.

[17] A.J.H. Al Gizi, M.W. Mustafa, K.M.A. Al Zaidi, M.K.J. Al-Zaidi, "Integrated PLC-fuzzy PID Simulink implemented AVR system", Electrical Power and Energy Systems, vol. 69 pp. 313-326, 2015.

[18] B. Şimşek, Y.T. İç, H.E. Şimşek, "A TOPSIS based Taguchi Optimization to Determine Optimal Mixture Proportions of the High Strength Self-Compacting Concrete" Chemometrics and Intelligent Laboratuary Systems, vol. 125, pp. 18-32, 2013.

[19] D.E. Seborg, T.F. Edgar, D.A. Mellichamp, F.J. Doyle, "Process Dynamics and Control", 3. rd., John-Wiley and Sons

[20] B. Şimşek, Y.T. İç, H.E. Şimşek, "A Full Factorial Design Based Desirability Function Approach for Optimization of Properties of C40/C50 Concrete Class", Math. Comput. Appl., vol. 18, no 3, pp. 330-339, 2013.

[21] S.M. Phadke, "Quality Engineering Using Robust Design", Prentice Hall, New Jersey, 1989.

[22] Y. Kuo, T. Yang, G.W. Huang, "The Use of a Grey-Based Taguchi Method for Optimizing Multi-Response Simulation Problems", Engineering Optimization, vol. 40, no. 6, pp. 517-528, 2008.

[23] C.Y. Chang, R. Huang, P.C. Lee, T.L. Weng, “Application of a Weighted Grey-Taguchi Method for Optimizing Recycled Aggregate Concrete Mixtures", Cement Concrete Comp., vol. 33, pp.1038-1049,2011. 